\title{
Simulation and Experimental Study of Photogeneration and Recombination in Amorphous-Like Silicon Thin Films Deposited by 27.12 MHz Plasma-Enhanced Chemical Vapor Deposition
}

\author{
Chia-Hsun Hsu, ${ }^{1}$ In-Cha Hsieh, ${ }^{1}$ Chia-Chi Tsou, ${ }^{2}$ and Shui-Yang Lien ${ }^{2}$ \\ ${ }^{1}$ Graduate Institute of Precision Engineering, National Chung Hsing University, Taichung 402, Taiwan \\ ${ }^{2}$ Department of Materials Science and Engineering, MingDao University, Changhua 52345, Taiwan
}

Correspondence should be addressed to Shui-Yang Lien; syl@mdu.edu.tw

Received 22 November 2012; Revised 3 May 2013; Accepted 16 May 2013

Academic Editor: Peter Rupnowski

Copyright (C) 2013 Chia-Hsun Hsu et al. This is an open access article distributed under the Creative Commons Attribution License, which permits unrestricted use, distribution, and reproduction in any medium, provided the original work is properly cited.

\begin{abstract}
Amorphous-like silicon (a-Si:H-like) thin films are prepared by $27.12 \mathrm{MHz}$ plasma-enhanced chemical vapor deposition technique. The films are applied to p-i-n single junction thin film solar cells with varying i-layer thickness to observe the effects on the shortcircuit current density, as well as the open-circuit voltage, fill factor, and conversion efficiency. The most significant experimental result is that $J_{\mathrm{sc}}$ has two different behaviors with increasing the i-layer thickness, which can be related to carrier collection efficiency in the long wavelength region. Furthermore, technology computer-aided design simulation software is used to gain better insight into carrier generation and recombination of the solar cells, showing that for the i-layer thickness of 200 to $300 \mathrm{~nm}$ the generation dominates the carrier density and thus $J_{\text {sc }}$, whereas for the i-layer thickness of 300 to $400 \mathrm{~nm}$ the recombination becomes the leading factor. The simulation results of cell performances are in good agreement with experimental data, indicating that our simulation has great reliability. In addition, the a-Si:H-like solar cells have low light-induced degradation, which in turn can have a great potential to be used for stable and high-efficiency solar cells.
\end{abstract}

\section{Introduction}

Hydrogenated amorphous silicon (a-Si:H) thin films have been widely studied in photovoltaic technology in recent years. Because of a high-absorption coefficient of a-Si: $\mathrm{H}$ in the visible range of the solar spectrum, $1 \mu \mathrm{m}$ thick a-Si:H layer is enough to absorb $90 \%$ of usable solar energy. However, large deviations in bonding angles and bonding lengths between the neighboring atoms in a-Si:H result in the weak or strained bonds, which would easily break and thus form defects in the atomic network. As a result, a-Si:H suffers from the photoinduced problem of degradation, known as StablerWronski effect, which reduces the efficiency of solar cells after light illumination. One alternative is the use of hydrogenated microcrystalline silicon ( $\mu \mathrm{c}-\mathrm{Si}: \mathrm{H})$, in which small crystals of highly ordered material in the range of tenths of nanometers are embedded. The amplitude of the degradation is a function of the crystallinity of the $\mu \mathrm{c}-\mathrm{Si}: \mathrm{H}$ layer: the lower the crystallinity, the higher the light-induced degradation. It is demonstrated more precisely that light-induced degradation is proportional to the ratio of the amorphous volume over the crystalline volume $[1,2]$. For solar cell applications the $\mu \mathrm{c}$-Si: $\mathrm{H}$ absorber is typically larger than $1 \mu \mathrm{m}$ representing an increase in production time and thus fabrication cost [3].

Recently a-Si:H-like materials, intermediate between a$\mathrm{Si}: \mathrm{H}$ and $\mu \mathrm{c}-\mathrm{Si}: \mathrm{H}$, have been deposited $[4,5]$. The films consist of silicon crystallites and/or clusters (less than $3 \mathrm{~nm}$ ) which is difficult to be observed from the morphology of the films. Further, a-Si:H-like films have the same optical absorption coefficient as a-Si:H but the improved transport properties of $\mu \mathrm{c}-\mathrm{Si}: \mathrm{H}$. In particular, the quantum efficiencymobility-lifetime $(\eta \mu \tau)$ product of electrons can be a factor of 
TABLE 1: Deposition conditions of the intrinsic and doped a-Si:Hlike layers.

\begin{tabular}{lcccc}
\hline Deposition condition & $\begin{array}{c}\text { p-type } \\
\text { a-SiC:H }\end{array}$ & $\begin{array}{c}\text { Buffer } \\
\text { layer }\end{array}$ & $\begin{array}{c}\text { Intrinsic } \\
\text { layer }\end{array}$ & $\begin{array}{c}\text { n-type } \\
\text { layer }\end{array}$ \\
\hline Power $(\mathrm{W})$ & 10 & 10 & 10 & 10 \\
Pressure $(\mathrm{Pa})$ & 90 & 90 & 90 & 60 \\
E/S $(\mathrm{mm})$ & 20 & 20 & 30 & 25 \\
Temperature $\left({ }^{\circ} \mathrm{C}\right)$ & 200 & 200 & 200 & 200 \\
$\mathrm{SiH}_{4}$ flow rate $(\mathrm{sccm})$ & 20 & 20 & 40 & 40 \\
$\mathrm{H}_{2}$ flow rate $(\mathrm{sccm})$ & 40 & 40 & 160 & 80 \\
$\mathrm{CH}_{4}$ flow rate $(\mathrm{sccm})$ & 18 & 18 & - & - \\
$\mathrm{B}_{2} \mathrm{H}_{6}$ flow rate $(\mathrm{sccm})$ & 5 & - & - & - \\
$\mathrm{PH}_{3}$ flow rate $(\mathrm{sccm})$ & - & - & - & 5 \\
Layer thickness $(\mathrm{nm})$ & 10 & 6 & $200-400$ & 30 \\
\hline
\end{tabular}

100 higher than that of typical a-Si:H in the as-deposited state, while $\eta \mu \tau$ product values after light soaking are comparable to typical a-Si:H before degradation [6-8]. Furthermore, the values of the deep defect density estimated from an analysis of modulated photocurrent (MPC) are about 10 times lower than those of typical a-Si:H [9]. Although the basic properties of a-Si:H-like films have been proposed, the application in solar cell research is not well investigated [6-12].

In this study, we apply the a-Si:H-like films to fabricate $\mathrm{p}-\mathrm{i}$-n single junction solar cells and vary the i-layer thickness from 200 to $400 \mathrm{~nm}$. Effects of the i-layer thickness on the device performances such as open-circuit voltage $\left(V_{\mathrm{oc}}\right)$, short-circuit current density $\left(J_{\mathrm{sc}}\right)$, fill factor $(\mathrm{FF})$, and conversion efficiency $(\eta)$ are investigated. We use $27.12 \mathrm{MHz}$ high-frequency plasma-enhanced chemical vapor deposition (HF-PECVD) to deposit silicon thin films, and the films almost always contain small crystalline fractions even under low $\mathrm{H}_{2} / \mathrm{SiH}_{4}$ gas ratios. This kind of a-Si:H-like films could also be obtained by $13.56 \mathrm{MHz}$ radio frequency PECVD but usually requiring a high $\mathrm{H}_{2} / \mathrm{SiH}_{4}$ ratio which might dramatically decrease the deposition rate. Moreover, technology computer-aided design simulation software (TCAD) is used to gain better insight into charge carrier generation and recombination of the devices.

\section{Experimental}

The a-Si:H-like single junction thin film solar cells were fabricated with structure of Asahi $\mathrm{SnO}_{2}: \mathrm{F}$-coated glass/p/buffer/i/ $\mathrm{n} / \mathrm{ZnO}: \mathrm{Al} / \mathrm{Ag}$. All of the Si layers were prepared by HFPECVD at a frequency of $27.12 \mathrm{MHz}$. Diborane $\left(\mathrm{B}_{2} \mathrm{H}_{6}\right)$ and phosphine $\left(\mathrm{PH}_{3}\right)$ gases were used as the doping gas to fabricate the a-Si:H-like p- and n-layers. To reduce the band offset between the energy bands of a wide band-gap ptype $\mathrm{SiC}(1.9 \mathrm{eV})$ and intrinsic layers, a buffer layer was used at the $\mathrm{p} / \mathrm{i}$ interface $[13,14]$. The detailed deposition conditions are summarized in Table 1. Five single junction solar cells were fabricated, and the i-layer thickness was varied from 200 to $400 \mathrm{~nm}$. The electrical, optical, and structural properties of the i-layer a-Si:H-like films are listed
TABLE 2: The properties of a-Si:H-like films compared to those of typical a-Si:H films.

\begin{tabular}{lcc}
\hline & a-Si:H & a-Si:H-like \\
\hline Crystallinity (\%) & - & 12 \\
Dark conductivity $\left(\Omega^{-1} \mathrm{~cm}^{-1}\right)$ & $1 \times 10^{-10}$ & $2.3 \times 10^{-10}$ \\
Photo conductivity $\left(\Omega^{-1} \mathrm{~cm}^{-1}\right)$ & $1 \times 10^{-5}$ & $6.1 \times 10^{-4}$ \\
Defect density $\left(\mathrm{cm}^{-3}\right)$ & $\sim 10^{16}$ & $10^{15}$ \\
Hydrogen content $($ at.\%) & 15 & 10 \\
Absorptivity at $400 \mathrm{~nm}\left(\mathrm{~cm}^{-1}\right)$ & $5 \times 10^{5}$ & $1.3 \times 10^{6}$ \\
Absorptivity at $600 \mathrm{~nm}\left(\mathrm{~cm}^{-1}\right)$ & $3.5 \times 10^{4}$ & $7.5 \times 10^{4}$ \\
Activation energy $(\mathrm{eV})$ & 0.8 & 0.76 \\
Band gap $(\mathrm{eV})$ & 1.8 & 1.67 \\
\hline
\end{tabular}

in Table 2 in comparison with a-Si:H. In Table 2, the values of the left column (a-Si:H) were obtained from [15]. The values of the right column (a-Si:H-like) were measured from our experimental films. The crystallinity was evaluated by microRaman spectroscopy. The dark conductivity was measured at room temperature using a source-measure unit (KEITHLEY 2400). The photoconductivity measurement was carried out under AM1.5G $\left(100 \mathrm{~mW} / \mathrm{cm}^{2}\right)$ of a solar simulator. The defect density was obtained by electron spin resonance (ESR). The bonded hydrogen content was determined by Fourier transform infrared (FTIR) spectroscopy. The absorptivity was obtained by means of UV-VIS spectrophotometer. The activation energy was calculated from temperature-dependent dark conductivity measurements. The band gap was estimated by a linear fit to a Tauc plot. The area of individual solar cells was defined by the $1 \times 1 \mathrm{~cm}^{2}$ sputtered $\mathrm{ZnO}: \mathrm{Al} / \mathrm{Ag}$ back contact. The film thickness was determined using an alpha-step profilometer. The solar cells were characterized by current density-voltage $(J-V)$ measurement under 1-sun (AM1.5G, $100 \mathrm{~mW} / \mathrm{cm}^{2}$ ) solar simulator irradiation and spectral response measurement from which external quantum efficiency (EQE) was obtained. The 1-sun standard light soaking test was performed in a climate chamber at $50^{\circ} \mathrm{C}$ for $500 \mathrm{~h}$ (IEC 61646).

To simulate thin film solar cells the commercially available software Silvaco TCAD, from Silvaco Inc., was used. The simulation program solved the Poisson equation coupled with the continuity equations of electrons and holes for the virtual device by dividing the whole structure into finite elements. The physical models that we used were ShockleyRead-Hall recombination model, concentration-dependent lifetimes, and low field mobility model. The photogeneration model, including a ray tracing algorithm, was used to calculate the absorption and transmission of light in the semiconductor layers. The solar cells considered here operate under the global standard solar spectrum (AM1.5G) illumination with $100 \mathrm{~mW} / \mathrm{cm}^{2}$ total incident power density. Table 3 lists the minimum set of input optical, electrical, and structural parameters used in this simulation without buffer layers between each layer. The theoretical values of the band mobility for a-Si:H-based thin films were around 1$10 \mathrm{~cm}^{2} \mathrm{~s}^{-1} \mathrm{~V}^{-1}$. The hole mobility was assumed to be smaller than the electron mobility. The i-layer thickness varied 
TABLE 3: The minimum set of input parameters used in our simulation work.

\begin{tabular}{|c|c|c|c|}
\hline Device parameter & \multicolumn{3}{|c|}{ Value } \\
\hline Device area $\left(\mathrm{um}^{2}\right)$ & \multicolumn{3}{|c|}{1} \\
\hline Average haze (\%) & \multicolumn{3}{|c|}{18} \\
\hline Exterior rear reflectance (\%) & \multicolumn{3}{|c|}{95} \\
\hline Light source & \multicolumn{3}{|c|}{ One sun (AM 1.5, $\left.100 \mathrm{~mW} / \mathrm{cm}^{2}\right)$} \\
\hline Layer parameters & p-layer & i-layer & n-layer \\
\hline Thickness (nm) & 10 & $200-400$ & 10 \\
\hline Doping concentration $\left(\mathrm{cm}^{-3}\right)$ & $1 \times 10^{18}$ & $1 \times 10^{10}$ & $1 \times 10^{19}$ \\
\hline Mobility gap (eV) & 1.92 & 1.67 & 1.7 \\
\hline Electron mobility $\left(\mathrm{cm}^{2} / \mathrm{Vs}\right)$ & 8 & 4 & 8 \\
\hline Hole mobility $\left(\mathrm{cm}^{2} / \mathrm{Vs}\right)$ & 2 & 0.7 & 2 \\
\hline Effective DOS in $\mathrm{CB}\left(\mathrm{cm}^{-3}\right)$ & $2.0 \times 10^{20}$ & $2.0 \times 10^{20}$ & $2.0 \times 10^{20}$ \\
\hline Effective DOS in VB $\left(\mathrm{cm}^{-3}\right)$ & $2.0 \times 10^{20}$ & $2.0 \times 10^{20}$ & $2.0 \times 10^{20}$ \\
\hline Dielectric constant & 11.9 & 11.9 & 11.9 \\
\hline Electron affinity $(\mathrm{eV})$ & 3.9 & 4 & 4 \\
\hline Tail state $\left(\mathrm{cm}^{-3}\right)$ & $10^{20}$ & $10^{20}$ & $10^{20}$ \\
\hline Gaussian-state $\left(\mathrm{cm}^{-3}\right)$ & $5 \times 10^{16}$ & $5 \times 10^{16}$ & $5 \times 10^{16}$ \\
\hline
\end{tabular}

between 200 and $400 \mathrm{~nm}$, while both p- and n-layers were fixed to $10 \mathrm{~nm}, 30 \mathrm{~nm}$, respectively. The average haze was set to be $18 \%$ for the device constructed with rough textured surfaces between layers. The distribution of states in the energy gap of a-Si:H assumed in the simulation is the general standard model of density of states (DOS), having two exponential band tails and two Gaussian distribution of states in the mobility gap $[15,16]$.

\section{Results and Discussion}

For each i-layer thickness, twenty solar cells were fabricated and they had very similar performances (error less than 5\%). Figure 1 is a representative result of $I-V$ curves of solar cells with different a-Si:H-like i-layer thickness. It can be seen that the cell with a $300 \mathrm{~nm}$ i-layer has the highest $J_{\mathrm{sc}}$ value of $17 \mathrm{~mA} / \mathrm{cm}^{2}$, while the other cells show $J_{\mathrm{sc}}$ values around 15.5$16 \mathrm{~mA} / \mathrm{cm}^{2}$. Only little variation in $V_{o c}$ is seen, and this may agree to that $V_{\text {oc }}$ would rather be affected by the qualities of thin film and $\mathrm{p} / \mathrm{i}$ interface $[17,18]$. From this result, the best combination of $V_{\mathrm{oc}}$ and $J_{\mathrm{sc}}$ can be found for an i-layer thickness of $300 \mathrm{~nm}$.

Figure 2 shows the EQE of the cells with different aSi:H-like i-layer thickness. The result is helpful to evaluate the carrier collection efficiency at a particular wavelength. It is found that the curves remain the same in the shortwavelength region $(<500 \mathrm{~nm})$ for each i-layer thickness due to the good performances of the p-doped layer [19]. But the curves vary in the long-wavelength region $(>500 \mathrm{~nm})$ with their peaks red-shifting. At the wavelength of $600 \mathrm{~nm}$, the $\mathrm{EQE}$ values for the thickness of $200-400 \mathrm{~nm}$ are $61 \%, 65 \%$, $69 \%, 68 \%$, and $63 \%$, respectively. It is interesting to clarify that the EQE differences in the long-wavelength region might result from the thickness variation rather than the crystalline fractions in the a-Si:H-like films. This can also be evidenced

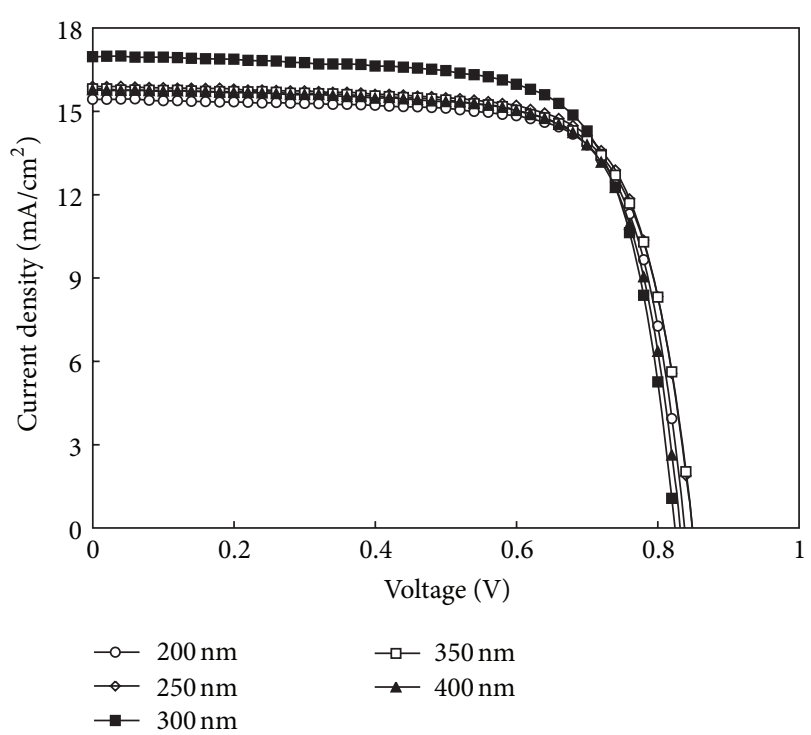

Figure 1: Experimental $I-V$ characteristics of a-Si:H-like solar cells with different i-layer thickness.

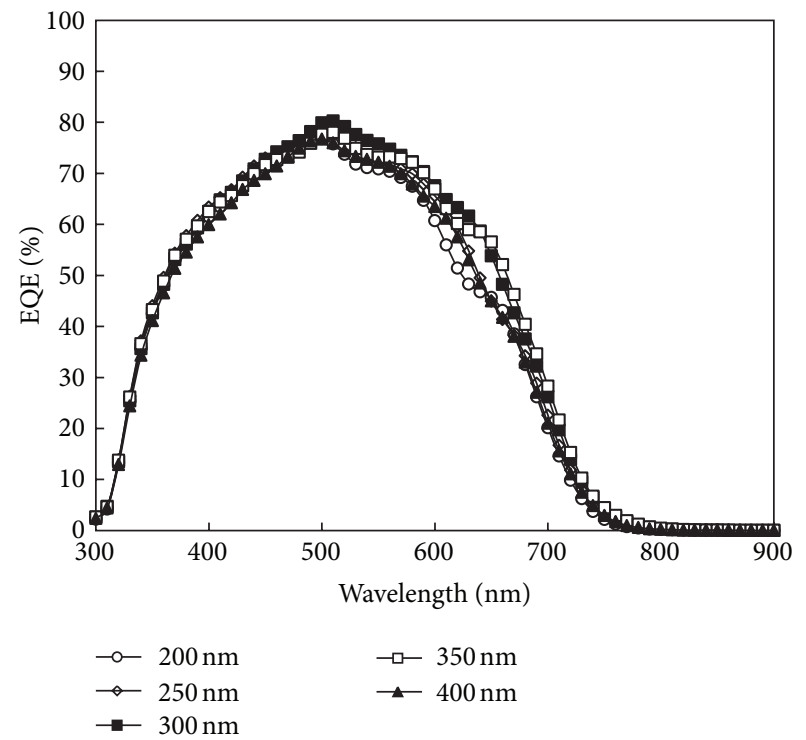

FIgURE 2: Experimental quantum efficiencies of a-Si:H-like solar cells with different i-layer thickness.

by the observation that the cutoff wavelength of each cell is about $800 \mathrm{~nm}$, same as that of a-Si:H.

Figure 3 shows a comparison of the i-layer thickness dependences between experimental (closed symbol) and simulation (open symbol) data. The simulation results show that FF monotonously decreases with the i-layer thickness due to the longer carrier transport length and thus increased series resistance. The $V_{\text {oc }}$ is calculated from [20]

$$
V_{\mathrm{oc}}=\frac{k t}{q} \ln \left(\frac{J_{\mathrm{sc}}}{J_{00}}\right)+\frac{q w_{d}^{2}}{2 \varepsilon}\left(\frac{N_{\mathrm{i}} N_{\mathrm{p}}}{N_{\mathrm{i}}+N_{\mathrm{p}}}\right),
$$

where $J_{00}$ is the temperature-independent saturation current, $w_{d}$ is the depletion width which usually equals to the i-layer 

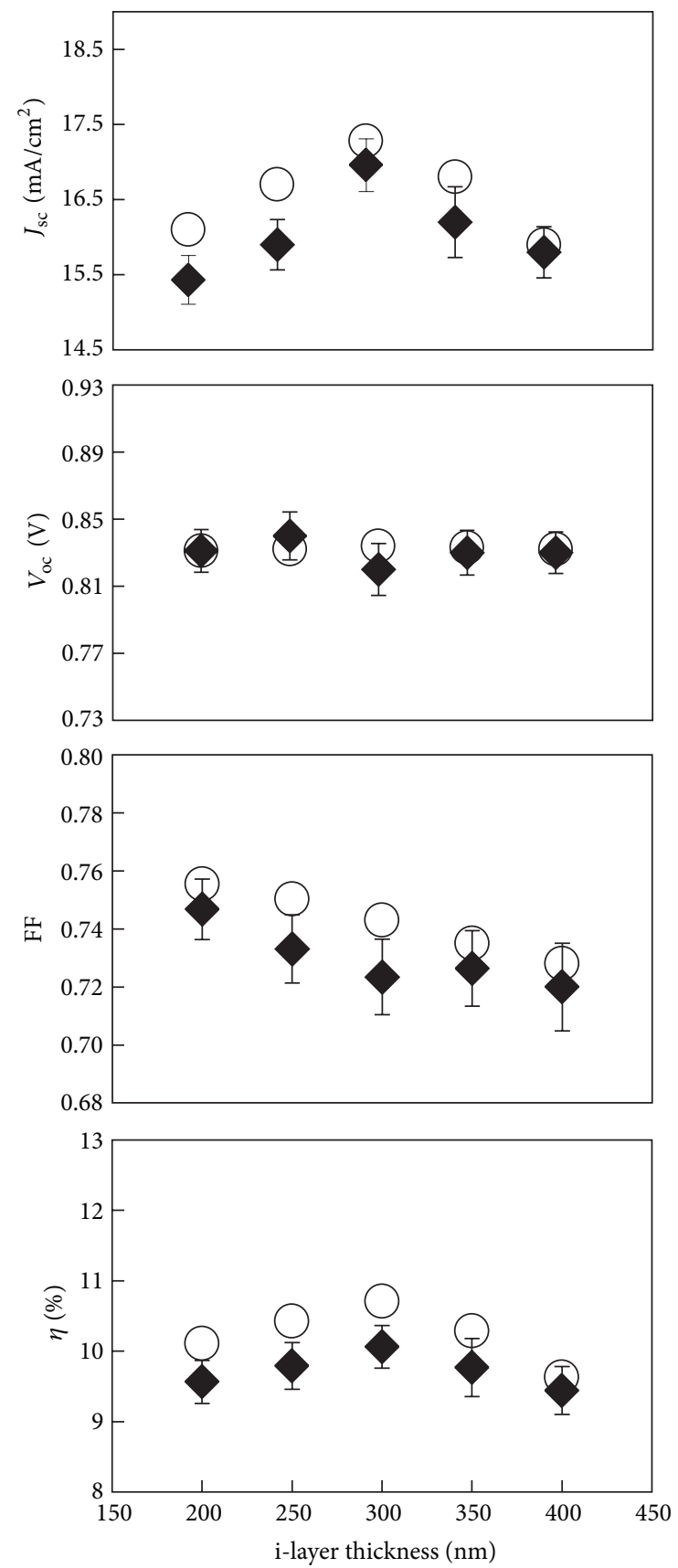

FIGURE 3: Simulated (open symbol) and experimental (closed symbol) results of external parameters of a-Si:H-like solar cells with different i-layer thickness.

thickness for a p-i-n device, and $N_{\mathrm{i}}$ and $N_{\mathrm{p}}$ are the majority carrier concentration in the i-layer and in the p-layer, respectively. The last part of the equation is the built-in voltage across the i-layer. Therefore, $V_{\mathrm{oc}}$ would vary depending on the values of $w_{d}$ and $J_{s c}$. For the i-layer thickness of 300-400 nm, the loss in $V_{\mathrm{oc}}$ caused by the decreased $J_{\mathrm{sc}}$ is compensated by the increased $w_{d}$. Finally, the trend of $\eta$ is similar to that of $J_{\text {sc }}$ implying that the cell efficiency is mainly dominated by $J_{\mathrm{sc}}$. Overall, the trends of the simulation results match well with that of experimental ones.

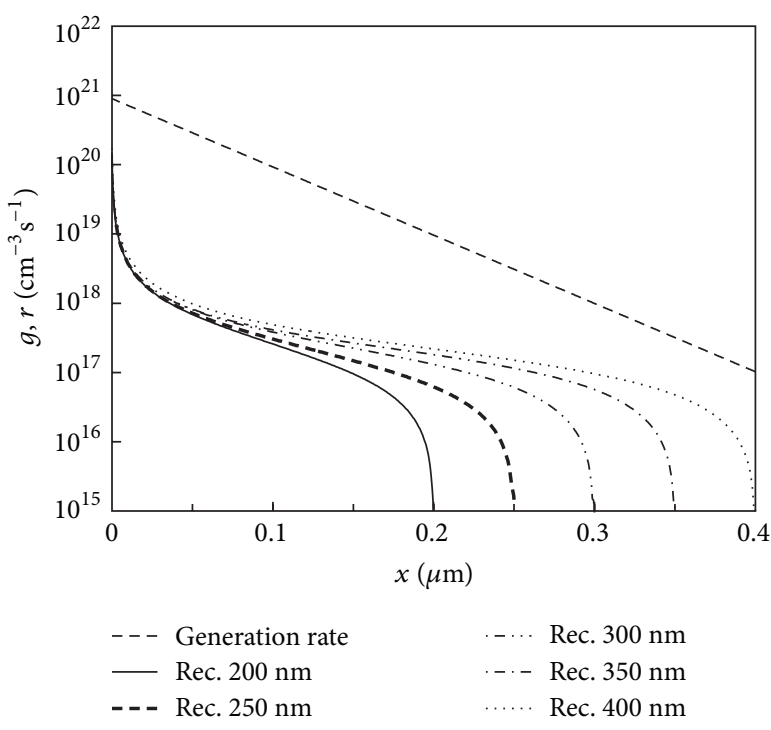

FIGURE 4: Simulated carrier generation rate and recombination rate as a function of the i-layer thickness.

Figure 4 shows the generation rate, $g(x)$, and the recombination rate, $r(x)$, of hole-electron pairs to further explain the $J_{\mathrm{sc}}$ behavior. In the textured i-layer, $g(x)$ with respect to a certain point, $x$, is based on [21]

$$
g(x)=\int\left[1-R^{2}(\lambda)\right] S(\lambda) \alpha(\lambda) e^{-\alpha x} d \lambda,
$$

where $R(\lambda)$ is the reflectance, $S(\lambda)$ the incident photon flux (photon $\mathrm{cm}^{-2} \mathrm{~s}^{-1}$ ) of the AM1.5G solar spectrum, and $\alpha(\lambda)$ the absorption coefficient. We assume $R$ is squared due to the textured surface that reduces the reflection. The $y$-axis scale is logarithmic showing that there is an enormously greater generation of electron-hole pairs near the front side of the i-layer, while further into the solar cell the generation rate exponentially decreases and finally becomes nearly constant. On the other hand, the recombination of charge carriers is assumed to be determined by Shockley-Read-Hall recombination with a recombination rate given by $[22,23]$

$$
r(x)=\frac{n(x) p(x)-n_{\mathrm{i}}^{2}}{\tau_{\mathrm{p}}\left[n(x)+n_{\mathrm{i}}\right]+\tau_{\mathrm{n}}\left[p(x)+n_{\mathrm{i}}\right]},
$$

where $n=n_{0}+\Delta n, p=p_{0}+\Delta p, n_{0}, p_{0}$ are the equilibrium carrier densities, $\Delta n, \Delta p$ are the excess carrier densities, $\tau_{\mathrm{n}}$, $\tau_{\mathrm{p}}$ are the carrier lifetimes at the dangling bond state $D^{0}$, and $n_{\mathrm{i}}$ is the intrinsic carrier density. Since most of photons are absorbed in the front part of the i-layer, the regions close to $\mathrm{p} / \mathrm{i}$ interface have a high recombination rate. The total generation, $G$, and the total recombination, $R$, in the i-layer can be given by

$$
\begin{gathered}
G=\int_{0}^{d} g(x) d x, \\
R=\int_{0}^{d} r(x) d x .
\end{gathered}
$$




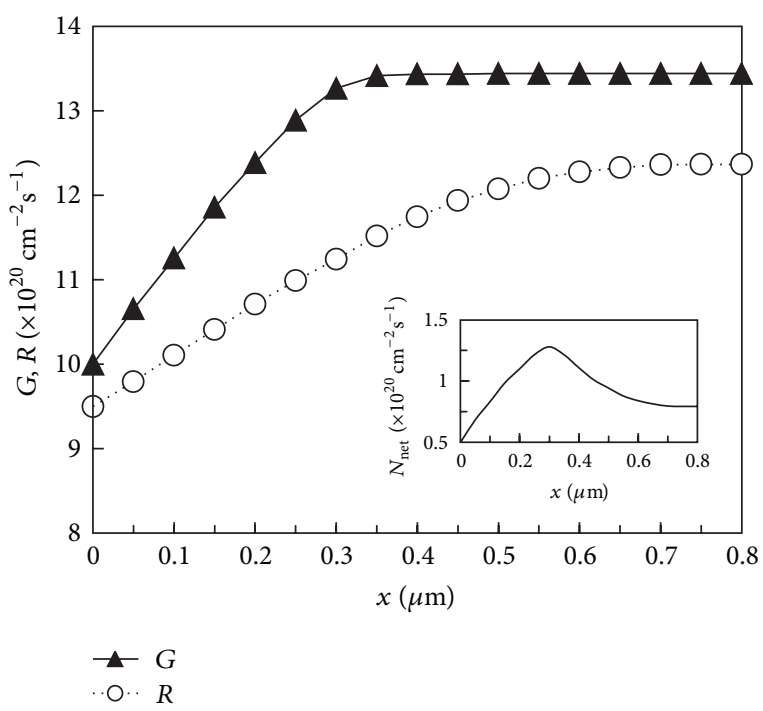

FIGURE 5: The total generation and recombination of solar cells with different i-layer thickness. The inset of Figure 6 shows the calculation result of the net charge carrier density for each i-layer thickness.

Note that the integral should be extended only from $x=0$ to the value of corresponding thickness, $d$. The calculation results are plotted in Figure 5. The total generation increases rapidly with the i-layer thickness, and a saturation occurs since the contribution at the deeper region of the i-layer can be neglected. Therefore, it is easy to obtain the net free carrier concentration, $N_{\text {net }}$, as given by

$$
N_{\text {net }}=G-R \text {. }
$$

The calculation result of $N_{\text {net }}$ is illustrated as an inset in Figure 5. The trend is consistent with that of $J_{\mathrm{sc}}$ observed from the experimental $I-V$ measurement. However, $N_{\text {net }}$ would finally be a constant indicating that $J_{s c}$ would still saturate after a temporary decrease. It is interesting that if the texture is not considered, the saturation of the generation will shift to the thick region. As a consequence, $N_{\text {net }}$ simply increases and then saturates without having a decrease.

Figure 6 shows the conversion efficiencies of the cells after $500 \mathrm{~h}$ exposure to $100 \mathrm{~mW} / \mathrm{cm}^{2}$ AM1.5G light for different i-layer thickness. It can be seen that degradation increases from $8.39 \%$ to $16.96 \%$ as i-layer thickness increases. The ilayer thickness of $300 \mathrm{~nm}$ shows the best stabilized efficiency of $9 \%$ and a degradation of $11 \%$ smaller than the typical value (>15\%) observed from a-Si:H solar cells. The $200 \mathrm{~nm}$ and $250 \mathrm{~nm}$ thick i-layers show lower initial efficiencies of $9.65 \%$ and $9.88 \%$, respectively, but their stabilized efficiencies are close to that of the $300 \mathrm{~nm}$ thick i-layer. Degradation in the cells with the 350 and $400 \mathrm{~nm}$ thick i-layer are about $13.2 \%$ and $16.9 \%$, respectively. Apparently, the thicker cells have a higher degradation, and this might be attributed to two reasons. First, a thick absorber leads to a weak electric field, which in turn decreases the carrier collection efficiency. Second, the total amount of the light-induced defects caused by the hydrogen out-diffusion from $\mathrm{Si}-\mathrm{H}$ bonds is larger

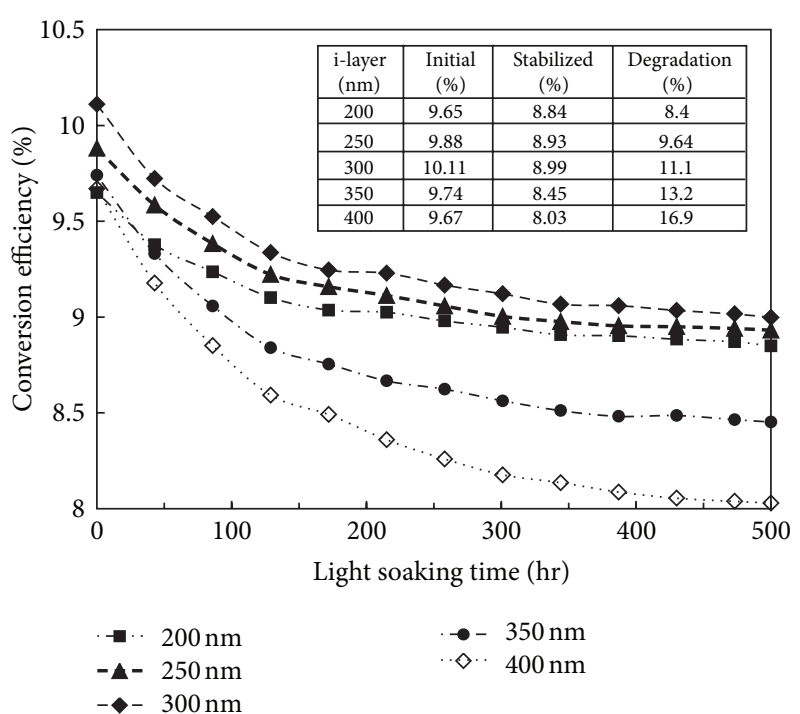

FIGURE 6: Light soaking effect for solar cells with different i-layer thickness.

for thicker absorbers. These defects will further flatten the electric field and thus increase the degradation.

\section{Conclusions}

In conclusion, the a-Si:H-like films deposited by $27.12 \mathrm{MHz}$ PECVD have been applied to $p-i-n$ single junction solar cells to investigate the influences on photovoltaic performances. The TCAD simulation result is in good agreement with the experimental data, showing great reliability. The carrier generation and recombination profiles are shown to explain the $J_{\mathrm{sc}}$ behavior. The generation dominates the device current density when the thin absorber is used, while for the thicker absorber the recombination begins to offset the current gain and results in a temporary reduction in $J_{\mathrm{sc}}$. The i-layer thickness of $300 \mathrm{~nm}$ can have the optimum balance between the generation and the recombination. The solar cell with the $300 \mathrm{~nm}$ i-layer also has a comparable initial efficiency and a low degradation compared to that of a-Si:H cells. As a result, the thin absorber and good stability make the a-Si:H-like material suitable for solar applications.

\section{Acknowledgments}

This work is sponsored by the BeyondPV Company and the National Science Council of the Republic of China under Contract nos. 100-2622-E-451-001-CC2, 100-2628-E-451-002MY2, and 101-3113-E-451-001-CC2.

\section{References}

[1] F. Finger, R. Carius, T. Dylla, S. Klein, S. Okur, and M. Günes, "Stability of microcrystalline silicon for thin film solar cell applications," IEE Proceedings, vol. 150, no. 4, pp. 300-308, 2003.

[2] Y. Wang, X. Geng, H. Stiebig, and F. Finger, "Stability of microcrystalline silicon solar cells with HWCVD buffer layer," Thin Solid Films, vol. 516, no. 5, pp. 733-735, 2008. 
[3] O. Vetterl, A. Lambertz, A. Dasgupta et al., “Thickness dependence of microcrystalline silicon solar cell properties," Solar Energy Materials and Solar Cells, vol. 66, no. 1-4, pp. 345-351, 2001.

[4] P. Roca i Cabarrocas, S. Hamma, S. N. Sharma, J. Costa, and E. Bertran, "Nanoparticle formation in low-pressure silane plasmas: bridging the gap between a-Si:H and $\mu \mathrm{c}-\mathrm{Si}$ films," Journal of Non-Crystalline Solids, vol. 227-230, no. 2, pp. 871-875, 1998.

[5] A. Fontcuberta I Morral, R. Brenot, E. A. G. Hamers, R. Vanderhaghen, and P. Roca i Cabarrocas, "In situ investigation of polymorphous silicon deposition," Journal of Non-Crystalline Solids, vol. 266-269, pp. 48-53, 2000.

[6] P. Roca i Cabarrocas, A. Fontcuberta i Morral, S. Lebib, and Y. Poissant, "Plasma production of nanocrystalline silicon particles and polymorphous silicon thin films for large-area electronic devices," Pure and Applied Chemistry, vol. 74, no. 3, pp. 359-367, 2002.

[7] P. St'ahel, S. Hamma, P. Sladek, and P. Roca i Cabarrocas, "Metastability studies in silicon thin films: from short range ordered to medium and long range ordered materials," Journal of NonCrystalline Solids, vol. 227, part 1, pp. 276-280, 1998.

[8] P. Roca i Cabarrocas, "Plasma deposition of silicon clusters: a way to produce silicon thin films with medium-range order?" Materials Research Society Symposium, vol. 507, p. 855, 1998.

[9] C. Longeaud, J. P. Kleider, P. Roca i Cabarrocas, S. Hamma, R. Meaudre, and M. Meaudre, "Properties of a new a-Si:H-like material: hydrogenated polymorphous silicon," Journal of NonCrystalline Solids, vol. 227-230, no. 1, pp. 96-99, 1998.

[10] A. Fontcuberta i Morral, R. Brenot, E. A. G. Hamers, R. Vanderhaghen, and P. Roca i Cabarrocas, "In situ investigation of polymorphous silicon deposition," Journal of Non-Crystalline Solids, vol. 266-269, pp. 48-53, 2000.

[11] K. H. Kim, E. V. Johnson, and P. Roca i Cabarrocas, "Irreversible light-induced degradation and stabilization of hydrogenated polymorphous silicon solar cells," Solar Energy Materials and Solar Cells, vol. 105, pp. 208-212, 2012.

[12] Y. Poissant, P. Chatterjee, and P. Roca i Cabarrocas, "No benefit from microcrystalline silicon $\mathrm{N}$ layers in single junction amorphous silicon p-i-n solar cells," Journal of Applied Physics, vol. 93, no. 1, pp. 170-174, 2003.

[13] B. Rech, C. Beneking, and H. Wagner, "Improvement in stabilized efficiency of a-Si:H solar cells through optimized $\mathrm{p} / \mathrm{i}$ interface layers," Solar Energy Materials and Solar Cells, vol. 41, pp. 475-483, 1996.

[14] S. N. Agbo, J. Krč, R. A. C. M. M. Van Swaaij, and M. Zeman, "Optimization of the pi interface properties in thin film microcrystalline silicon solar cell," Solar Energy Materials and Solar Cells, vol. 94, no. 11, pp. 1864-1868, 2010.

[15] R. E. I. Schropp and M. Zeman, Amorphous and Microcrystalline Silicon Solar Cells: Modeling, Materials and Device Technology, Kluwer Academic Publishers, Dordrecht, The Netherlands, 1998.

[16] R. A. Street, Hydrogenated Amorphous Silicon, Cambridge University, Cambridge, UK, 1991.

[17] L. Jiang, J. H. Lyou, S. Rana, E. A. Schiff, Q. Wang, and Q. Yua, "Open-circuit voltage physics in amorphous silicon solar cells," Materials Research Society Symposium Proceedings, vol. 609, article A18.3, 2000.

[18] A. Klaver and R. A. C. M. M. van Swaaij, "Modeling of lightinduced degradation of amorphous silicon solar cells," Solar Energy Materials and Solar Cells, vol. 92, no. 1, pp. 50-60, 2008.
[19] J. Meier, R. Fluckiger, H. Keppner, and A. Shah, "Complete microcrystalline $p-i-n$ solar cell-Crystalline or amorphous cell behavior?" Applied Physics Letters, vol. 65, no. 7, pp. 860862, 1994.

[20] A. E. Delahoy, J. Britt, and Z. Kiss, "Annual subcontract report," NREL Report NREL/TP-413-5334, 1993.

[21] A. Hamel and A. Chibani, "Characterization of texture surface for solar cells," Journal of Applied Sciences, vol. 10, no. 3, pp. 231234, 2010.

[22] W. Shockley and W. T. Read, "Statistics of the recombinations of holes and electrons," Physical Review, vol. 87, no. 5, pp. 835-842, 1952.

[23] R. N. Hall, "Electron-hole recombination in germanium," Physical Review Letters, vol. 87, no. 2, p. 387, 1952. 

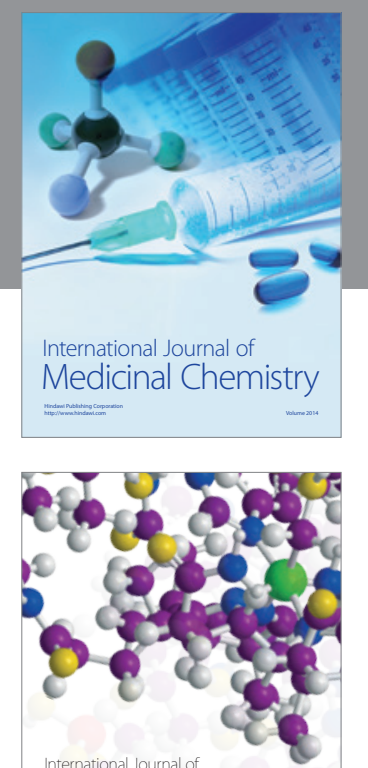

\section{Carbohydrate} Chemistry

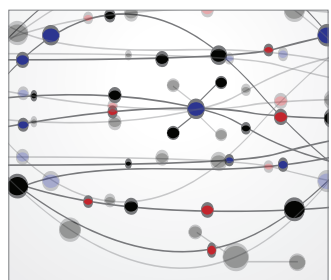

The Scientific World Journal
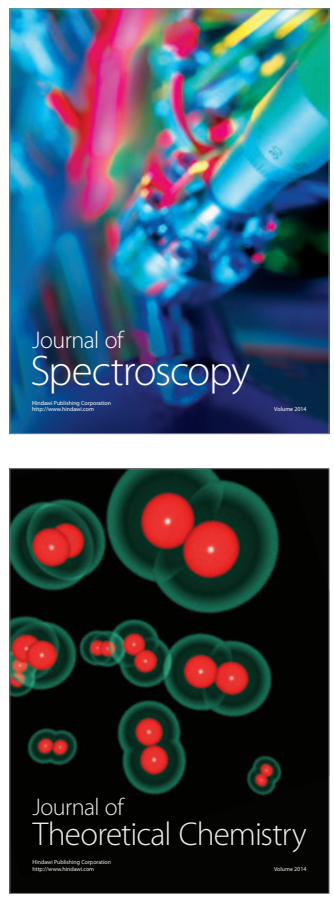
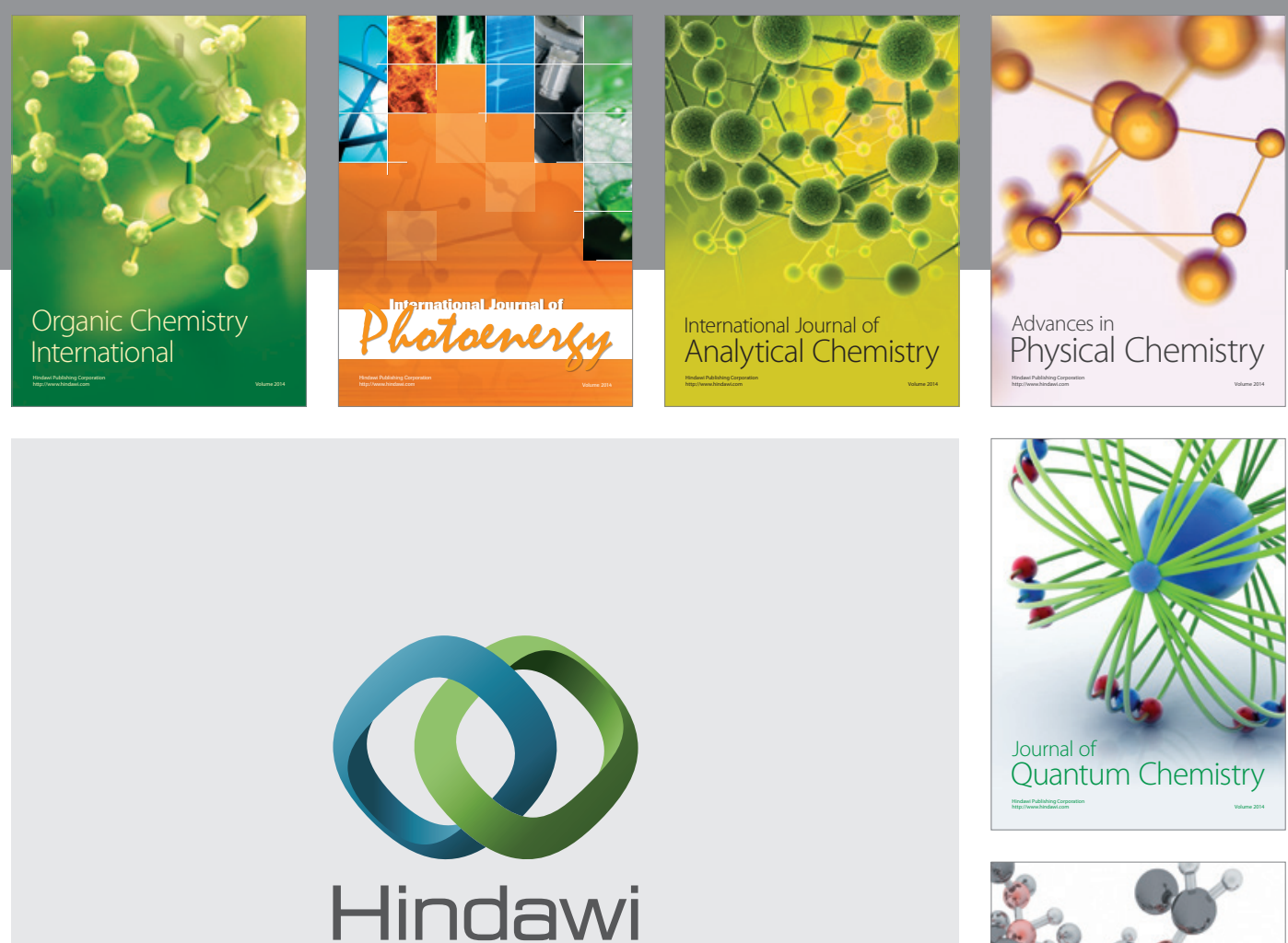

Submit your manuscripts at

http://www.hindawi.com

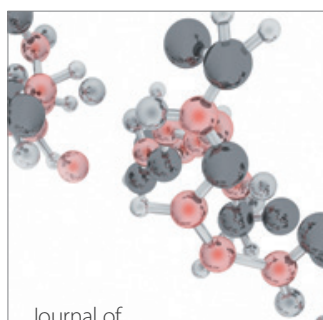

Analytical Methods

in Chemistry

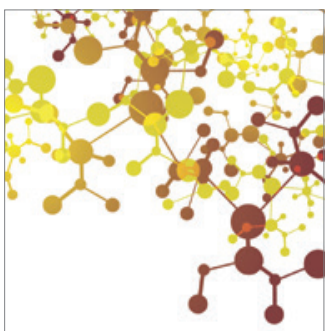

Journal of

Applied Chemistry

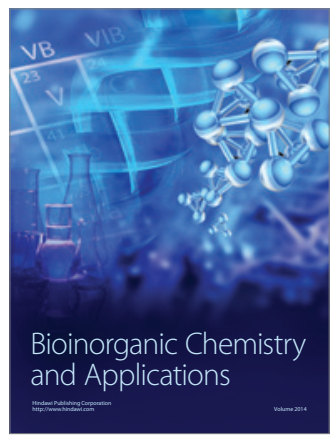

Inorganic Chemistry
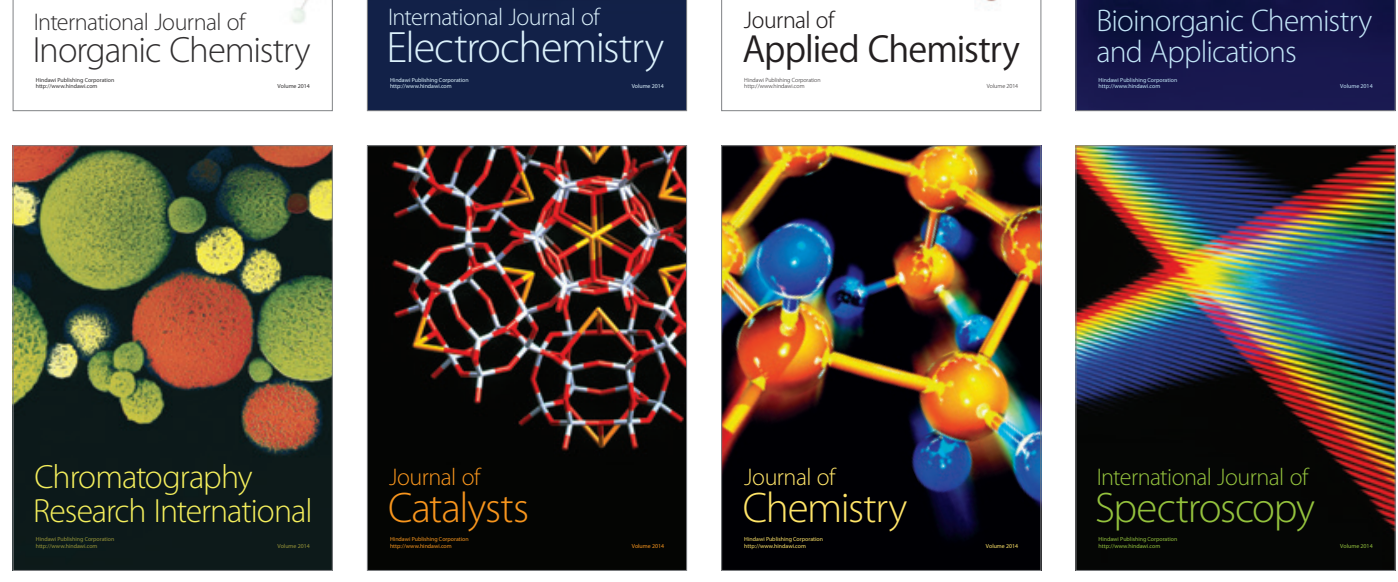